\title{
Lactic Acidosis in a Newborn With Adrenal Calcifications
}

\author{
ALEXANDRA ZECIC, JOÉL E. SMET, CLAUDINE M. DE PRAETER, PIET VANHAESEBROUCK, CARLO VISCOMI, \\ CAROLINE VAN DEN BROECKE, BOEL DE PAEPE, PETER LOHSE, JEAN-JACQUES MARTIN, JOSHUA G. JACKSON, \\ COLIN R. CAMPBELL, LINDA J. DE MEIRLEIR, MASSIMO ZEVIANI, SARA H. SENECA, WILLY LISSENS,
} AND RUDY N. VAN COSTER

\begin{abstract}
Departments of Neonatology [A.Z., C.M.P., P.V.], Pediatric Neurology and Metabolism [J.E.S., B.P., R.V.C.], and Pathology [C.B.], Ghent University Hospital, Ghent 9000, Belgium; Department of Molecular Neurogenetics [C.V., M.Z.], Istituto Nazionale Neurologico “C. Besta," Milan 20126, Italy; Department of Clinical Chemistry [P.L.], University of Munich, Munich 81377, Germany; Department of Neuropathology [J.-J.M.], Antwerp University, Antwerp 2610, Belgium; Department of Pharmacology [J.G.J., C.R.C.], University of Minnesota Medical School, Minneapolis, Minnesota 55455; Department of Medical Genetics [L.J.M., S.H.S., W.L.], University Hospital
\end{abstract}

Brussels, Brussels 1090, Belgium

\begin{abstract}
A patient is reported who presented in the newborn period with an unusual combination of congenital lactic acidosis and bilateral calcifications in the adrenal medulla, visible on standard abdominal x-ray and ultrasound examination. At birth, the proband was hypotonic and dystrophic. She developed respiratory insufficiency, cardiomegaly, and hepatomegaly and died at the age of $38 \mathrm{~d}$. Examination of postmortem heart muscle revealed multiple areas of myocardial infarction with dystrophic calcifications. In the medulla of the adrenal glands, foci of necrosis and calcifications, and in the liver, multiple zones of necrosis and iron deposition were detected. Biochemical analysis in heart muscle revealed a decreased activity of complex IV of the oxidative phosphorylation (OXPHOS) and in liver a combined deficiency involving the complexes I, III, IV, and V. The findings were suggestive of a defect in biosynthesis of the mitochondrially encoded subunits of the OXPHOS complexes. Extensive analysis of the proband's mitochondrial DNA revealed neither pathogenic deletions and point mutations nor copy number alterations. Relative amounts of mitochondrial transcripts for the ribosomal mitochondrial 12S rRNA (12S) and mitochondrial 16S rRNA (16S) were significantly increased suggesting a compensatory mechanism involving the transcription machinery to low levels of translation. The underlying molecular defect has not been identified yet. (Pediatr Res 66: 317-322, 2009)
\end{abstract}

$\mathrm{C}^{\mathrm{s}}$ ongenital lactic acidosis refers to a group of inborn errors of metabolism characterized in the neonatal period by metabolic acidosis associated with an overwhelming accumulation of lactate. Most frequently, a defect in one of the complexes of the oxidative phosphorylation (OXPHOS) or in the pyruvate dehydrogenase complex is found. Other causes of congenital lactic acidosis are defects in pyruvate carboxylase, phosphoenolpyruvate carboxykinase, or fumarase.

Bilateral calcifications in the adrenal medulla are seldom seen in newborns. In patients with Wolman disease, bilateral adrenal calcifications are typically found. Wolman disease is a rapidly fatal disorder caused by severe deficiency of the

Received February 25, 2009; accepted April 10, 2009.

Correspondence: Rudy N. Van Coster, M.D., Ph.D., Division of Pediatric Neurology and Metabolism, Department of Pediatrics, University Hospital Ghent, De Pintelaan 185, B 9000 Ghent, Belgium; e-mail: rudy.vancoster@ugent.be

Supported by grants from the Fund for Scientific Research (FWO) Belgium, contract grant number G.0666.06 (Universiteit Gent, Vrije Universiteit Brussel), and the Kid-AuQuai foundation. lysosomal acid lipase but is not associated with congenital lactic acidosis. Adrenal calcifications can also occur as a result of adrenal hemorrhage after breech or other traumatic deliveries, or in association with sepsis.

Here, we report a newborn patient with a combination of congenital lactic acidosis and bilateral calcifications in the adrenal medulla visible on standard imaging studies. The clinical, biochemical, radiologic, and postmortem findings in this patient are described.

\section{CASE REPORT}

The patient was the first child of healthy, nonconsanguineous parents. Prenatal ultrasound examination at $21 \mathrm{wk}$ of pregnancy revealed intrauterine growth retardation and pericardial effusions. Amniocentesis performed at $25 \mathrm{wk}$ of pregnancy showed a normal karyotype (46, XX). PCR for toxoplasmosis in the amniotic fluid was negative. Virus isolation from amniotic fluid yielded negative results. Analysis of the mother's serum failed to detect IgM antibodies specific for toxoplasmosis, rubella, varicella zoster, cytomegalovirus, and parvovirus B19. The proband was born after induction of labor at $38 \mathrm{wk}$. Anthropometric measurements were compatible with symmetrical growth retardation (birth weight $1840 \mathrm{~g}$, head circumference $30.5 \mathrm{~cm}$ and birth length $42 \mathrm{~cm}$ ). She was pale and hypotonic at birth and had respiratory insufficiency necessitating intubation and artificial ventilation. The liver was enlarged. Abdominal $\mathrm{x}$-rays and ultrasound examination both showed bilateral calcifications in the adrenal glands (Fig. $1 A, C)$. Laboratory investigations revealed a metabolic acidosis $\left(\mathrm{pH} 7.11, \mathrm{pCO}_{2} 51.6 \mathrm{~mm} \mathrm{Hg}\right.$, bicarbonate $16.2 \mathrm{mM}$ and base excess $-15.4 \mathrm{mM})$ and high serum lactate $(21 \mathrm{mM}$, normal $<2 \mathrm{mM}$ ). She had a normovolemic anemia ( $\mathrm{Hb} 7.4$ $\mathrm{g} / \mathrm{dL}$ ) with increased number of normoblasts (30 per $100 \mathrm{RBC}$, normal <3-4). A negative Kleihauer-Betke test excluded fetomaternal hemorrhage. Over the next few days, she devel-

Abbreviations: 12S, mitochondrial 12S rRNA; 16S, mitochondrial 16S rRNA; BN-PAGE, blue native polyacrylamide gel electrophoresis; COXI, mRNA encoding subunit I of complex IV; mtDNA, mitochondrial DNA; OXPHOS, oxidative phosphorylation 


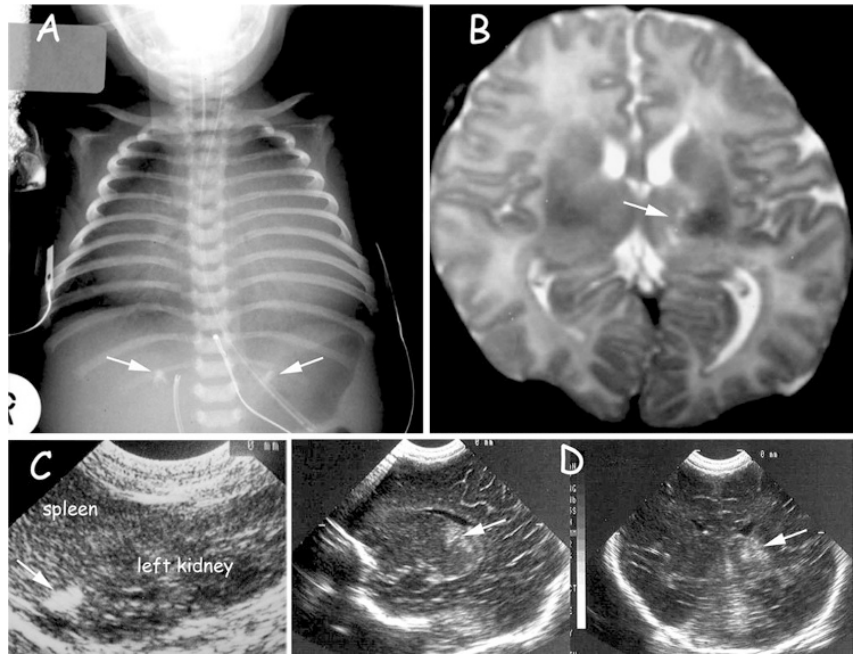

Figure 1. Bilateral adrenal calcifications detected on abdominal x-ray $(A)$ and by ultrasound examination (arrow) (C). Postmortem MRI axial T2weighted sequence showing abnormal signal intensities in the left thalamus (arrow) (B). Parasagittal and coronal view of a cranial ultrasound examination showing the hyperdense lesions in the left thalamus (arrow) $(D)$.

oped moderate, transient thrombocytopenia. In blood, the concentrations of calcium $(10.9 \mathrm{mg} / \mathrm{dL}$, normal 8.6-10.6) and phosphor $(4.6 \mathrm{mg} / \mathrm{dL}$, normal 3.1-5.9) were normal. The results of the coagulations studies were normal (PTT $33 \mathrm{~s}$, PT $80 \%$, and fibrinogen $258 \mathrm{mg} / \mathrm{dL}$ ). A right ventricular hypertrophy, pulmonary hypertension and minimal pericardial effusions were detected by echocardiography. Bicarbonate infusions were administered repeatedly for correction of metabolic acidosis. The pulmonary hypertension was treated with inhaled nitric oxide (iNO) and tolazoline. Her condition stabilized and the hemodynamic state remained stable. Metabolic acidosis, however, persisted and $48 \mathrm{~h}$ after birth serum lactate was still $17 \mathrm{mM}$. Aspartate aminotransferase (AST) was normal ( $84 \mathrm{U} / \mathrm{L}$, normal $14-86 \mathrm{U} / \mathrm{L})$, alanine aminotransferase (ALT) slightly increased (58 U/L, normal 13-45 U/L), and creatinine kinase (CK) was normal, as was the ammoniemia. The amino acid profile in serum was normal except for an increase of alanine concentration $(680 \mathrm{microM}$, normal 200-467 microM). The urinary organic acid profile showed massive lactic aciduria, moderate ketonuria, and presence of 2-OH and 2-oxo-acids. Acylcarnitine profile in blood was normal. Negative results for congenital infections included cytomegalovirus ( $\operatorname{IgM})$, herpes simplex virus ( $\operatorname{IgM})$, EpsteinBarr (IgM), enterovirus, and adenovirus. Chromosomal analysis on white blood cells from the proband confirmed the normal karyogram $(46, \mathrm{XX})$. A biopsy of skin and skeletal muscle (Quadriceps) was performed at the age of $24 \mathrm{~d}$. The patient remained ventilator dependent. Hepatomegaly and severe cardiomegaly persisted. Ultrasound examination of the brain showed hyperdense lesions in the left thalamus (Fig. $1 D)$. In accordance with parent's wishes, intensive care was withdrawn at day 38. Postmortem MRI of the brain confirmed the presence of a lesion with abnormal signal intensities in the left thalamus (Fig. 1B). Autopsy was performed $1 \mathrm{~h}$ after death.

\section{METHODS}

Macroscopic and microscopic examination of postmortem tissues including brain, heart muscle, adrenal glands, liver, and skeletal muscle were performed, as well as electron microscopic examination of skeletal muscle and skin. Spectrophotometrical analysis of the OXPHOS complexes in liver, skeletal muscle, heart muscle, and cultured skin fibroblasts was done according to the methods described earlier: complex I (NADH coenzyme Q reductase, rotenone sensitive) (1), complex II (succinate co-enzyme Q reductase, malonate sensitive) (2), complex II + III (succinate cytochrome $c$ reductase) $(3,4)$, complex III (ubiquinol-cytochrome $c$ reductase) (4), complex IV (cytochrome $c$ oxidase) (5), and citrate synthase (6). Protein content was measured according to Lowry's method (7). Blue native polyacrylamide gel electrophoresis (BN-PAGE) analysis for separation and visualization of the OXPHOS complexes was performed in mitochondria isolated from liver (8). Cultured skin fibroblasts were used for immunocytochemical staining and liver and heart tissue for immunohistochemical staining as described earlier (9). The antibodies used for immunostaining studies were NDUFS7 for complex I, IP subunit for complex II, core2 subunit for complex III, subunit I for complex IV, and the alpha-subunit for complex V (Molecular Probes, Eugene, OR). The search for pathologic alterations and mutations in skeletal muscle mitochondrial DNA (mtDNA) was performed using southern blot, PCR-single strand conformational polymorphism (PCR-SSCP), and denaturing HPLC (dHPLC, MitoScreen Assay Kit, Transgenomic). The quantitative mtDNA assessment was addressed by relative quantification of total mtDNA to nuclear DNA by real time PCR (ABI Prism 7500 Sequence Detection System, Applied Biosystems) in total cellular DNA isolated from heart muscle of the patient, as well as in similar tissue from age-matched control individuals (10). Relative quantification of liver mitochondrial transcripts was performed by SYBR-GREEN real time PCR (ABI Prism 7000 sequence detection system). Each reaction was performed in triplicate with the following profile: one cycle at $50^{\circ} \mathrm{C}$ for $2 \mathrm{~min}$, one cycle at $95^{\circ} \mathrm{C}$ for $10 \mathrm{~min}$, and then 40 cycles at $95^{\circ} \mathrm{C}$ for $15 \mathrm{~s}$ and $60^{\circ} \mathrm{C}$ for $1 \mathrm{~min}$. A final dissociation step $\left(95^{\circ} \mathrm{C}\right.$ for $15 \mathrm{~s}, 60^{\circ} \mathrm{C}$ for $20 \mathrm{~s}$, and $95^{\circ} \mathrm{C}$ for $\left.15 \mathrm{~s}\right)$ was added to assess for unspecific primer amplifications. Total RNA was extracted from liver specimen by Trizol, according to manufacturer instructions (Invitrogen, Carlsbad, CA). Two microgram of total RNA was treated with RNase-free DNase and retrotranscribed by using the "cDNA cycle" kit (Invitrogen). Approximately, 2-5 ng of cDNA was used for real-time amplification of mitochondrial $12 \mathrm{~S}$ rRNA (12S), mitochondrial 16S rRNA (16S), mRNA encoding subunit I of complex IV (COXI), and nuclear glyceraldehyde-3-phosphate dehydrogenase (GAPDH). The following oligo pairs were used:

12S: FOR: cccagggttggtcaattt; REV: tacgecggcttctattgact

16S: FOR: gctaaacctagccccaaacc; REV: gcgecaggtttcaatttcta COI: FOR: gcttctgactcttacctccetct; REV: ceggcetccactatagca GAPDH: FOR: cccagggttggtcaattc; REV: tacgccggcttctattgact.

The skeletal muscle biopsy specimen and the skin taken at the age of $24 \mathrm{~d}$ as well as the postmortem tissue samples were obtained for diagnostic purpose after informed consent and with approval of the Institutional Review Board (Medical Ethics Committee University and University Hospital Ghent, Belgium).

\section{RESULTS}

Macroscopic and microscopic examination. External examination of the brain showed no anomalies. On section, a cystic lesion $(0.5 \mathrm{~cm}$ diameter) was seen in the left thalamus. Microscopic examination of this lesion revealed a pseudocyst with accumulation of macrophages and loss of tissue. In addition, multiple small confluent lesions were detected. In one of these lesions, calcifications were noticed along with neuronal remnants. In another lesion, gliosis and spongy degeneration was seen dispersed between a few intact neurons. The neocortex, hippocampus, and the rest of the white matter were normal. Examination of the heart showed multiple areas of myocardial infarction with dystrophic calcifications (Fig. 2A, B). The myocytes had a prominent branching architecture, and interstitial fibrosis was seen between myocytes. The nuclei were slightly pleomorphic with irregular contours. Occasionally, myocytes were seen with their sarcolemma 


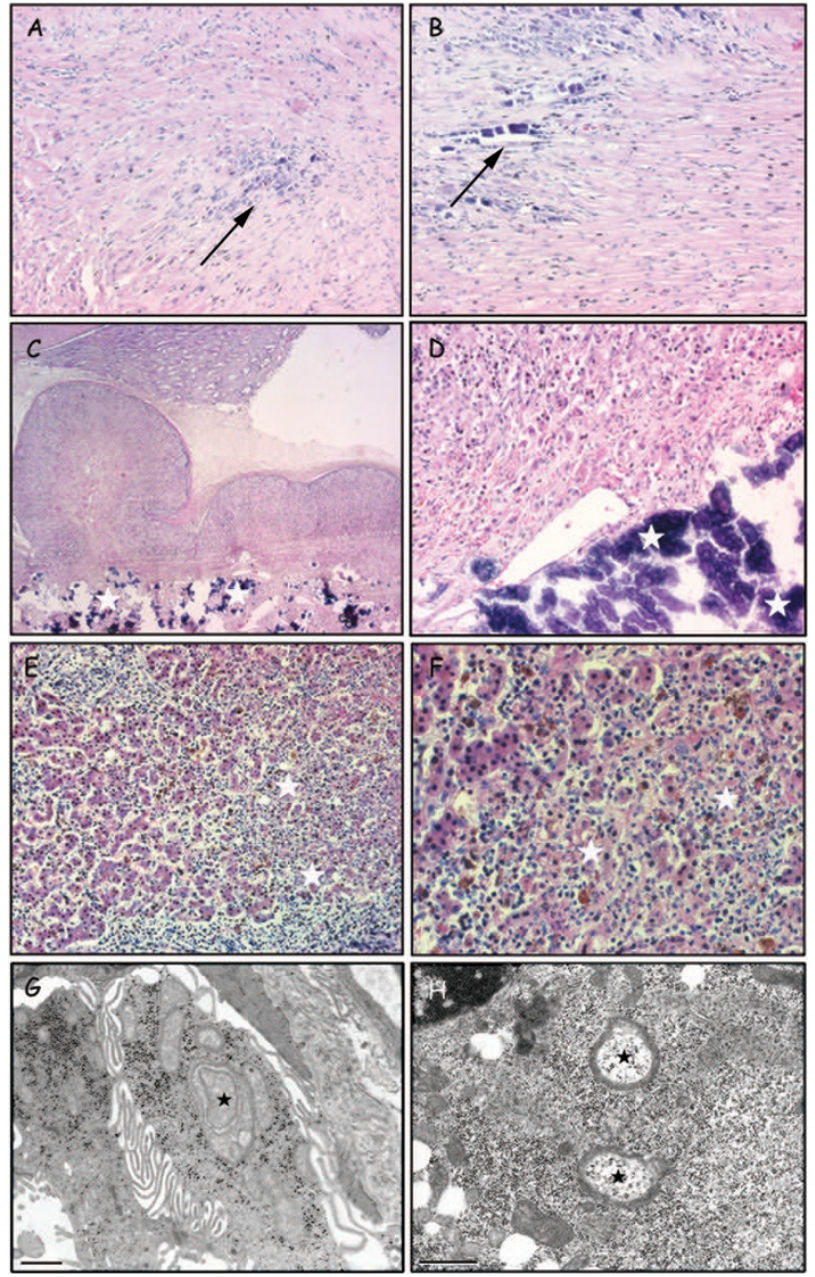

Figure 2. Light microscopic examination of the heart showing interstitial fibrosis with dystrophic calcifications (arrow), hematoxylin-eosin, $\times 100(A)$, $\times 200(B)$. Light microscopic examination of the adrenal glands showing normal cortex and extensive calcifications in the medulla (asterisk), hematoxylin-eosin, $\times 40(C), \times 200(D)$. Light microscopic examination of the liver showing multiple irregular necrotic areas with transition between normal hepatocytes and necrotic tissue (asterisk), hematoxylin-eosin, $\times 100(E)$, $\times 200(F)$. Electron miscroscopy of the skin showing the presence of abnormal mitochondria with concentric cristae (asterisk) in a clear cell of an eccrine sweat gland, (glutaraldehyde-osmium tetroxide fixation, araldite inbedding, uranyl acetate, and lead citrate contrast, $\times 11.600$, scale $=1 \mu \mathrm{m}(G)$. Electron microscopy of skeletal muscle showing large abnormal mitochondria (asterisk) with peripherally disposed concentric cristae between free beta-glycogen particles in a muscle fiber, $\times 16.800$, scale $=1 \mu \mathrm{m}(H)$.

filled with macrophages. Examination of the adrenal glands revealed foci of necrosis with calcifications in the medulla (Fig. 2C, D). In the lungs, interstitial pneumonia with signs of acute respiratory distress syndrome (ARDS) and bronchopulmonary dysplasia were detected. Liver examination showed multiple necrotic zones with deposition of iron (Fig. 2E, F). The portal areas were enlarged and proliferation of bile ducts was seen. Skeletal muscle examination showed in each field one to four large muscle fibers and many small fibers. The large muscle fibers contained granular densities, fat droplets, and internal nuclei. The small muscle fibers showed large variation in diameter and some had centrally located nuclei. Typical ragged-red fibers were not seen. No significant dif- ferences were seen between the findings in the biopsy specimen and the postmortem specimen. Light microscopic examination of skin was normal.

Electron microscopic examination. Electron microscopic analysis of skeletal muscle showed in the large fibers myofibrillary disorganization and broadened $\mathrm{Z}$ bands. In some of these fibers, nuclei were centralized. Multiple fat droplets and free beta-glycogen particles forming large subsarcolemmal and intermyofibrillary masses were seen, as well as large mitochondria (1 $\mu \mathrm{m}$ diameter) with abnormal, concentric cristae. The small muscle fibers had normal sarcomeric organization. Nuclei were centralized. Large numbers of glycogen particles and fat droplets were occasionally seen. Electron microscopic analysis of skin showed abnormal mitochondria in the tangle of the sweat glands (Fig. 2G). Mitochondria were enlarged (diameter $1.5 \mu \mathrm{m}$ ), and the cristae were concentric and rolled up at the periphery (Fig. $2 H$ ).

Biochemical studies and BN-PAGE. Analysis of mitochondria isolated from patient's liver revealed decreased activities of the OXPHOS complexes I, III, IV, and V and a normal activity of complex II (Table 1). The decreased activities of the complexes I, III, IV, and V in liver were confirmed by catalytic staining of the OXPHOS complexes in the BNPAGE gel (Fig. 3). Subcomplexes of complex V were detected in the BN-PAGE gel following ATPase staining (Fig. 3 ). In homogenate from heart muscle spectrophotometric analysis showed a reduced activity of complex IV and a low normal activity of complex I. The citrate synthase activity was low in homogenate from heart revealing relatively low abundance of mitochondria in heart but was not considered deficient. In mitochondria isolated from patient's skeletal muscle, spectrophotometric analysis showed normal activities of the OXPHOS complexes (Table 1). Biochemical analysis of cultured skin fibroblasts from the patient revealed normal activities of the OXPHOS complexes, the pyruvate dehydrogenase complex and pyruvate carboxylase. Mutation analysis of the LIPA gene that encodes the lysosomal acid lipase did not reveal any significant abnormality.

Immunocytological and immunohistochemical studies. The patient's cultured skin fibroblasts showed normal immunocytochemical staining pattern for all five OXPHOS complexes. Immunohistochemical staining in heart paraffin sections showed normal staining for complex $\mathrm{I}$ to $\mathrm{V}$ in cardiomyocytes. Immunohistochemical analysis in liver revealed negative staining for complex IV, reduced staining for complex III, and an inhomogeneous staining pattern for complex I. In contrast, staining for complex II and complex V was normal.

Mitochondrial DNA analysis. Real time PCR performed on total cellular DNA isolated from liver supports the interpretation that the mtDNA copy numbers were within normal limits (see methods for details). Standard analysis of patient-derived material failed to detect the presence of mtDNA deletions or point mutations associated with Mitochondrial myopathy, Encephalopathy, LactAcidosis, and Stroke-like lesions (MELAS, m.3243A $>$ G), Myoclonic Epilepsy and Ragged-Red Fibers (MERRF, m.8344A $>$ G, Neuropathy, Ataxia and Retinitis Pigmentosa (NARP, 
Table 1. OXPHOS activities in different tissues from the patient and controls measured by spectrophotometric analysis

\begin{tabular}{|c|c|c|c|c|c|c|c|}
\hline Tissue & Fraction & $\begin{array}{l}\text { Complex } \\
\text { I/CS }\end{array}$ & $\begin{array}{l}\text { Complex } \\
\text { II/CS }\end{array}$ & $\begin{array}{l}\text { Complex } \\
\text { III/CS }\end{array}$ & $\begin{array}{c}\text { Complex } \\
\text { IV/CS }\end{array}$ & $\begin{array}{l}\text { Complex } \\
\text { V/CS }\end{array}$ & $\mathrm{CS}^{*}$ \\
\hline \multirow[t]{2}{*}{ Liver } & Isolated mitochondria & 0.41 & 1.10 & 0.67 & 0.53 & 0.40 & 158 \\
\hline & Controls $(n=17)$ & $0.69 \pm 0.07$ & $0.98 \pm 0.09$ & $0.91 \pm 0.09$ & $1.03 \pm 0.08$ & $0.79 \pm 0.09$ & $263 \pm 128$ \\
\hline \multirow[t]{2}{*}{ Heart muscle } & Homogenate & 0.56 & 0.67 & ND & 0.84 & ND & 597 \\
\hline & Controls $(n=13)$ & $0.66 \pm 0.05$ & $0.72 \pm 0.06$ & & $0.90 \pm 0.03$ & & $975 \pm 208$ \\
\hline \multirow[t]{2}{*}{ Skeletal muscle } & Isolated mitochondria & 0.75 & 0.83 & 0.74 & 0.96 & 0.74 & 828 \\
\hline & Controls $(n=30)$ & $0.72 \pm 0.06$ & $0.82 \pm 0.05$ & $0.81 \pm 0.08$ & $0.97 \pm 0.04$ & $0.79 \pm 0.06$ & $830 \pm 335$ \\
\hline \multirow[t]{2}{*}{ Cultured fibroblasts } & Homogenate & ND & 0.63 & 0.72 & 0.86 & ND & 121 \\
\hline & Controls $(n=30)$ & & $0.64 \pm 0.06$ & $0.73 \pm 0.09$ & $0.92 \pm 0.04$ & & $123 \pm 40$ \\
\hline
\end{tabular}

Control sample ratios are given as mean $\pm \mathrm{SD}$.

* Specific activity is expressed as nanomoles of substrate per minute per milligram of protein. All other data are expressed as the logarithm of OXPHOS activity divided by the logarithm of citrate synthase activity.

CS, citrate synthase; ND, not determined.
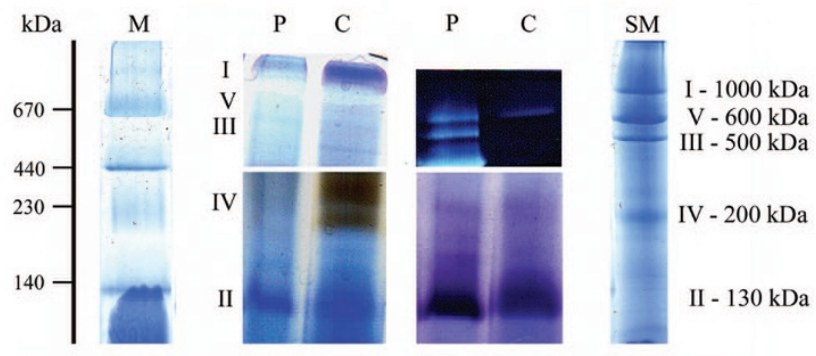

Figure 3. Separation of the OXPHOS complexes by BN-PAGE. $M$, molecular weight markers; $P$, proband's liver (mitochondrial fraction); $C$, control liver (mitochondrial fraction); $S M$, control skeletal muscle (mitochondrial fraction). Left panel, molecular weight markers. Mid panel, catalytic staining in the gel after separation of the OXPHOS complexes by BN-PAGE. In the patient, the activities of the complexes I and IV are decreased, whereas complex II is normal, compared with the control (left part of mid panel). The upper part of the gel with one lane from the patient and one lane from the control is used for complex I staining, the lower part of the same gel for complex IV and II staining. Catalytic staining in the gel for complex V shows complex V and subcomplexes of complex $\mathrm{V}$ in the patient. In the control, only one complex $\mathrm{V}$ band (holo-complex) is visualized (right part of mid panel). The upper part of the gel with one lane from the patient and one lane from the control is used for complex V staining (in reflection mode). The lower part of the same gel is used for complex II staining. The activities of complex II were comparable in the patient and control. Right panel, the five OXPHOS complexes are visible because of the presence of Coomassie blue after separation by BN-PAGE. Their relative position in the gel is demonstrated.

m.8993T $>$ G/C), and Leber Hereditary Optic Neuropathy (LHON, m.11778G $>$ A, m.14484T $>$ C, m.3460G $>$ A, m.14459G $>$ A). Additional analysis failed to detect any pathogenic nucleotide alteration in any of the 22 mitochondrial tRNA, two rRNA or 13 polypeptides genes encoded by the mitochondrial genome. Overall, no indication of mtDNA degradation was observed in any of the methods used for mtDNA analysis.

Mitochondrial transcripts analysis. The levels of mitochondrial transcripts in the liver of the proband and age matched controls were investigated by real time PCR. Surprisingly, increased levels of $12 \mathrm{~S}$ and $16 \mathrm{~S}$ and of COXI were detected (Fig. 4). The 16S showed a 6-fold increase and the $12 \mathrm{~S}$ a 3 -fold increase in the patient's liver, suggesting a compensatory mechanism involving the transcription and translation machineries.

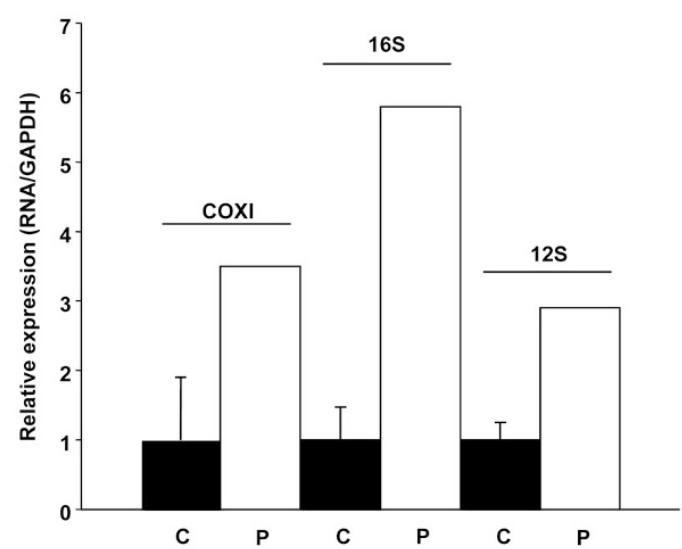

Figure 4. Analysis of mitochondrial transcripts COXI, 16S, and $12 \mathrm{~S}$ by real time PCR. Data are expressed relative to GAPDH. The control value is the mean of three different controls $\pm \mathrm{SD}$.

\section{DISCUSSION}

A female patient is described here who presented in the newborn period with an unusual combination of abnormal clinical, biochemical, radiologic, and postmortem findings. Clinical characteristics were symmetrical growth retardation, hypotonia, hepatomegaly, respiratory insufficiency, and hypertrophic cardiomyopathy. Laboratory investigations revealed a severe congenital lactic acidosis, and imaging studies detected bilateral calcifications in the adrenal medulla. In the brain, hyperdense lesions were seen with ultrasound examination unilaterally in the thalamus. The combination of lactic acidosis and bilateral adrenal calcifications in a newborn patient has not been reported previously. Bilateral adrenal calcifications are rarely seen at birth and can result from adrenal hemorrhage from fetal origin, or after traumatic delivery. In the proband, the bilateral adrenal calcifications were confined to the medulla and were not detected in the adrenal cortex. Also, the adrenal structure was preserved. This is in contrast with the findings seen in the patients with adrenal hemorrhage and subsequent calcifications. In the latter, the adrenal triangularly folded structure is lost, and the calcifications are not confined to the medulla. Few case reports describe the association of adrenal calcifications with congenital nephrotic syndrome (11), disseminated herpes simplex infection (12), and congenital cytomegalovirus infection (13), al- 
though in a quite different clinical setting. Bilateral adrenal calcifications are also seen in patients with Wolman disease (14), a progressive condition characterized by hepatosplenomegaly, abdominal distention, and failure to thrive during the first months of life. Congenital lactic acidosis, however, has not been reported in these patients. Wolman disease is caused by a deficiency of the lysosomal acid lipase resulting in intralysosomal accumulation of lipids ultimately leading to impairment of normal cell function and organ failure (15). In the proposita, the postmortem findings showed no evidence of massive lipid storage. Furthermore, mutation analysis of the gene coding for the lysosomal acid lipase did not reveal any significant abnormality.

Typically, defects in one of the OXPHOS complexes, the pyruvate dehydrogenase complex or in one of the enzymes involved in gluconeogenesis were described in association with congenital lactic acidosis. In the proband, it was clear that the lactic acidosis resulted from the defects in the OXPHOS system as documented in liver, and to a lesser degree in heart muscle. In liver, the activities of complexes I, III, IV, and $\mathrm{V}$ were decreased, whereas the activity of complex II was normal. In heart muscle, the activity of complex IV was decreased. The complexes I, III, IV, and V contain subunits encoded by the mitochondrial genome, whereas complex II is composed of four subunits all encoded by the nuclear genome. The complexes I and IV contain the highest number of mitochondrial-encoded subunits and therefore are more vulnerable to mtDNA defects. Together, these findings were suggestive of an mtDNA defect. The detection of subcomplexes of complex $\mathrm{V}$ may also point to an mtDNA defect (16). Complex V has only two subunits, (subunits 6 and 8) which are encoded by the mitochondrial genome. These two subunits are involved in linking the intramembranous portion of complex V to its globular domain. Decreased intramitochondrial synthesis results in more globular parts of complex $\mathrm{V}$ to become dissociated from the intramembranous parts (17). The globular parts can be visualized as smaller subcomplexes compared with the holo-complex V in a BN-PAGE gel stained with ATPase.

A defect in the mtDNA could explain the abnormalities detected in the mitochondria from the patient. Extensive analysis of the mtDNA, however, failed to detect any abnormality. Classical point mutations (MELAS, MERRF, NARP, or LHON mutations) were not found. A complete mitochondrial genome screening did not identify any pathogenic alteration in one of the 37 mitochondrial genes. Relative quantification of the total mtDNA of liver versus nuclear DNA disclosed normal results. No indication of mtDNA damage was found.

Intramitochondrial synthesis of the mitochondrially encoded subunits of the OXPHOS complexes not only requires intact mtDNA and a normal copy number of mtDNA but also requires a number of nuclearly encoded proteins involved in transcription and translation. Nine patients with a defect in one of those proteins were reported until now. Two siblings with pathogenic mutation in the gene encoding the mitochondrial elongation factor G1 (EFG1) had severe growth retardation and signs of liver failure in the neonatal period (18). The heart was normal. In both the patients, a combined deficiency of complex I and IV was documented. Another patient with pathogenic mutation in EFG1 presented with early-onset Leigh syndrome (19). A patient with mutation in the gene coding for the mitochondrial elongation factor $\mathrm{Tu}(\mathrm{EFTu})$ presented with repeated episodes of acute metabolic acidosis, hyperlactacidemia and was found to have macrocystic leukodystrophy and polymicrogyria on MRI (19). Two patients with mutation in TSFM, a gene coding for the mitochondrial translation elongation factor EFTs, were also reported (20). One of them presented in the neonatal period with encephalomyopathy and the other with severe concentric cardiomyopathy. The mitochondrial transcripts ND6, COXI, mRNA encoding subunit II of complex IV (COXII), and 12S rRNA were normal in these two patients. Patients with defects in mitochondrial ribosomal proteins were also reported. One had a pathogenic mutation in MRPS16 encoding a highly conserved mitochondrial ribosomal protein (21). The enzymatic activities of complex I and IV were decreased in skeletal muscle and liver. The abundance of one mitochondrial transcript (12S rRNA) was markedly decreased, whereasother transcripts (16S, ND1, COXI, and ND6) were normal. Two siblings with a defect in another mitochondrial ribosomal protein (MRPS22) were reported by Saada et al. (22). In both patients, three mitochondrial transcripts (COXII, 12S, and $16 \mathrm{~S})$ were significantly decreased. All nine patients had severe lactic acidosis but in none of them tissue calcifications were detected. To our surprise, mitochondrial transcripts in the proband's liver were increased, suggesting a compensatory mechanism involving the transcription machinery. The defect could be related to the mitochondrial translation system. The 6 -fold increase in $16 \mathrm{~S}$ and a 3 -fold increase in $12 \mathrm{~S}$ could reflect a compensatory mechanism to low levels of translation. The absence of mtDNA depletion/deletion and the absence of point mutations in the mitochondrial tRNA genes suggest that a mutation in a nuclear gene encoding a translational factor could be responsible for the defects seen in the proband.

In the literature, three patients were reported with a combination of OXPHOS defects and calcifications. The patient reported by Robinson et al. (23) had congenital lactic acidosis, cerebral calcifications, and a combined deficiency of the OXPHOS complexes. Postmortem examination revealed alterations in basal ganglia and calcifications in the periventricular white matter but not in heart muscle nor in adrenal medulla. The profile of the biochemical abnormalities was different from that found in the proband. The activities of succinate cytochrome $c$ reductase (complex II + III), complex IV, and pyruvate dehydrogenase complex were deficient in cultured skin fibroblasts and skeletal muscle but normal in liver. The two sibs reported by Van Straaten et al. (24) had fatal intractable lactic acidosis in the neonatal period and calcifications in the hemispheric subcortical white matter. The activities of the complexes I and IV were decreased in skeletal muscle and liver but normal in cultured skin fibroblasts. In these two sibs, extensive cerebral malformations were detected, which was not the case in the patient presented here.

Although the underlying molecular defect could not be detected in the patient presented here, the clinical, radiologic, biochemical, and morphologic characteristics are peculiar. 
The combination of lactic acidosis and prominent bilateral adrenal calcifications in a neonate has not been published earlier. Reports of additional patients with similar characteristics might help to find the underlying molecular defect in these patients.

Acknowledgments. We thank Chantal de Groote (Universitaire Instelling Antwerpen) for performing the ultrastructural studies and Mary Phelan for help in correcting the English language.

\section{REFERENCES}

1. Fischer JC, Ruitenbeek W, Gabreëls FJ, Janssen AJ, Renier WO, Sengers RC, Stadhouders AM, ter Laak HJ, Trijbels JM, Veerkamp JH 1986 A mitochondrial encephalomyopathy: the first case with an established defect at the level of coenzyme Q. Eur J Pediatr 144:441-444

2. Rustin P, Chretien D, Bourgeron T, Gérard B, Rötig A, Saudubray JM, Munnich A 1994 Biochemical and molecular investigations in respiratory chain deficiencies. Clin Chim Acta 228:35-51

3. Sottocasa GL, Kuylenstierna B, Ernster L, Bergstrand A 1967 An electrontransport system associated with the outer membrane of liver mitochondria. A biochemical and morphological study. J Cell Biol 32:415-438

4. Birch-Machin MA, Shepherd IM, Watmough NJ, Sheratt HS, Bartlett K, DarleyUsmar VM, Milligan DW, Welch RJ, Aynsley-Green A, Turnbull DM 1989 Fatal lactic acidosis in infancy with a defect of complex III of the respiratory chain. Pediatr Res 25:553-559

5. DiMauro S, Servidei S, Zeviani M, DiRocco M, DeVivo DC, DiDonato S, Uziel G, Berry K, Hoganson G, Johnsen SD 1987 Cytochrome c oxidase deficiency in Leigh syndrome. Ann Neurol 22:498-506

6. Srere PA 1969. Citrate synthase, EC 4.1.3.7. citrate oxaloacetate-lyase (CoAacetylating). In: Löwenstein JM (ed, Methods in Enzymology, Vol 13. Academic Press, London, pp 3-11

7. Lowry OH, Rosebrough NJ, Farr AL, Randall RJ 1951 Protein measurement with the Folin phenol reagent. J Biol Chem 193:265-275

8. Van Coster R, Smet J, George E, De Meirleir L, Seneca S, Van Hove J, Sebire G, Verhelst H, De Bleecker J, Van Vlem B, Verloo P, Leroy J 2001 Blue native polyacrylamide gel electrophoresis: a powerful tool in diagnosis of oxidative phosphorylation defects. Pediatr Res 50:658-665

9. De Paepe B, Smet J, Leroy JG, Seneca S, George E, Matthys D, van Maldergem L, Scalais E, Lissens W, De Meirleir L, Meulemans A, Van Coster R 2006 Diagnostic value of immunostaining in cultured skin fibroblasts from patients with oxidative phosphorylation defects. Pediatr Res 59:2-6
10. De A, Campbell C 2007 A novel interaction between DNA ligase III and DNA polymerase gamma plays an essential role in mitochondrial DNA stability. Biochem J 402:175-186

11. Indumathi CK, Dinakar C, Lewin S, Phadke KD 2005 Congenital nephrotic syndrome with adrenal calcification and cardiac malformation. Indian. J Pediatr 72:1049-1051

12. Morrison SC, Comisky E, Fletcher BD 1988 Calcification in the adrenal glands associated with disseminated herpes simplex infection. Pediatr Radiol 18:240-241

13. Magnin D 1973 Calcification of the adrenal gland and cytomegalovirus infection in early childhood. Helv Paediatr Acta 28:135-143

14. Wolman M, Sterk VV, Gatt S, Frenkel M 1961 Primary familial xanthomatosis with involvement and calcification of the adrenals. Report of two more cases in siblings of a previously described infant. Pediatrics 28:742-757

15. Lohse P, Maas S, Lohse P, Elleder M, Kirk JM, Besley GT, Seidel D 2000 Compound heterozygosity for a Wolman mutation is frequent among patients with cholesteryl ester storage disease. J Lipid Res 41:23-31

16. Carrozzo R, Wittig I, Santorelli FM, Bertini E, Hofmann S, Brandt U, Schägger H 2006 Subcomplexes of human ATP synthase mark mitochondrial biosynthesis disorders. Ann Neurol 59:265-275

17. Nijtmans LG, Henderson NS, Attardi G, Holt IJ 2001 Impaired ATP synthase assembly associated with a mutation in the human ATP synthase subunit 6 gene. J Biol Chem 276:6755-6762

18. Coenen MJ, Antonicka H, Ugalde C, Sasarman F, Rossi R, Heister JG, Newbold RF, Trijbels FJ, van den Heuvel LP, Shoubridge EA, Smeitink JA 2004 Mutant mitochondrial elongation factor G1 and combined oxidative phosphorylation deficiency. N Engl J Med 351:2080-2086

19. Valente L, Tiranti V, Marsano RM, Malfatti E, Fernandez-Vizarra E, Donnini C, Mereghetti P, De Gioia L, Burlina A, Castellan C, Comi GP, Savasta S, Ferrero I, Zeviani M 2007 Infantile encephalopathy and defective mitochondrial DNA translation in patients with mutations of mitochondrial elongation factors EFG1 and EFTu. Am J Hum Genet 80:44-58

20. Smeitink JA, Elpeleg O, Antonicka H, Diepstra H, Saada A, Smits P, Sasarman F, Vriend G, Jacob-Hirsch J, Shaag A, Rechavi G, Welling B, Horst J, Rodenburg RJ, van den Heuvel B, Shoubridge EA 2006 Distinct clinical phenotypes associated with a mutation in the mitochondrial translation elongation factor EFTs. Am J Hum Genet 79:869-877

21. Miller C, Saada A, Shaul N, Shabtai N, Ben-Shalom E, Shaag A, Hershkovitz E, Elpeleg O 2004 Defective mitochondrial translation caused by a ribosomal protein (MRPS16) mutation. Ann Neurol 56:734-738

22. Saada A, Shaag A, Arnon S, Dolfin T, Miller C, Fuchs-Telem D, Lombes A, Elpeleg O 2007 Antenatal mitochondrial disease caused by mitochondrial ribosomal protein (MRPS22) mutation. J Med Genet 44:784-786

23. Robinson BH, Chow W, Petrova-Benedict R, Clarke JT, Van Allen MI, Becker LE, Boulton JE, Ragan I 1992 Fatal combined defects in mitochondrial multienzyme complexes in two siblings. Eur J Pediatr 151:347-352

24. Van Straaten HL, Van Tintelen JP, Trijbels JM, van den Heuvel LP, Troost D, Rozemuller JM, Duran M, de Vries LS, Schuelke M, Barth PG 2005 Neonatal lactic acidosis, complex I/IV deficiency, and fetal cerebral disruption. Neuropediatrics 36:193-199 